\title{
The two-day wave in the Antarctic and Arctic mesosphere and lower thermosphere
}

\author{
V. M. Tunbridge and N. J. Mitchell \\ Department of Electronic and Electrical Engineering, University of Bath, Bath, UK \\ Received: 21 January 2009 - Published in Atmos. Chem. Phys. Discuss.: 24 April 2009 \\ Revised: 16 July 2009 - Accepted: 8 August 2009 - Published: 3 September 2009
}

\begin{abstract}
There have been comparatively few studies reported of the 2-day planetary wave in the middle atmosphere at polar latitudes. Here we report on a study made using high-latitude meteor radars at Rothera in the Antarctic $\left(68^{\circ} \mathrm{S}, 68^{\circ} \mathrm{W}\right)$ and Esrange in Arctic Sweden $\left(68^{\circ} \mathrm{N}\right.$, $21^{\circ} \mathrm{E}$ ). Observations from 2005-2008 are used for Rothera and from 1999-2008 for Esrange. Measurements were made of horizontal winds at heights of $80-100 \mathrm{~km}$. The radar data revealed distinct summertime and wintertime 2-day waves. The Antarctic summertime wave occurs with significant amplitudes in January - February at heights between about 88$100 \mathrm{~km}$. Horizontal wind monthly variances associated with the wave exceed $160 \mathrm{~m}^{2} \mathrm{~s}^{-2}$ and the zonal component has larger amplitudes than the meridional. In contrast, the Arctic summertime wave occurs for a longer duration, JuneAugust and has meridional amplitudes larger than the zonal amplitudes. The Arctic summertime wave is weaker than that in the Antarctic and maximum monthly variances are typically $60 \mathrm{~m}^{2} \mathrm{~s}^{-2}$. In both hemispheres the summertime wave reaches largest amplitudes in the strongly sheared eastward zonal flow above the zero-wind line and is largely absent in the westward flow below. The observed differences in the summertime wave are probably due to the differences in the background zonal winds in the two hemispheres. The Antarctic and Arctic wintertime 2-day waves have very similar behaviour. The Antarctic wave has significant amplitudes in May-August and the Arctic wave in November-February. Both are evident across the full height range observed.
\end{abstract}

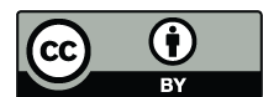

Correspondence to: V. M. Tunbridge (vt211@bath.ac.uk)

\section{Introduction}

The quasi-2-day, or 2-day, wave is a prominent feature of the mesosphere and lower thermosphere (MLT) region. It is observed each year around summer solstice. It has been observed in measurements of winds, temperature and geopotential height. In the wind field, the amplitude of the wave can exceed $20 \mathrm{~ms}^{-1}$ near the mesopause, making it the largest amplitude planetary wave observed at mesopause heights.

First observations of the wave were reported by Muller (1972). The wave has since been extensively studied by ground-based radar. In particular, meteor and MF radars have been used to investigate the vertical structure and climatology of the wave at middle and low latitudes (e.g., Salby and Roper, 1980; Craig et al., 1983; Plumb et al., 1987; Tsuda et al., 1988; Harris and Vincent, 1993; Palo and Avery, 1996; Jacobi et al., 1997; Thayaparan et al., 1997; Jacobi et al., 1998; Gurubaran et al., 2001; Manson et al., 2004; Pancheva et al., 2004; Riggin et al., 2004). Satellite observations have been used to investigate the global-scale structure of the wave (e.g., Rodgers and Prata, 1981; Wu et al., 1993; Ward et al., 1996; Lieberman, 1999; Limpasuvan and Wu, 2003; Smith, 2003; Riggin et al., 2004; Sandford et al., 2008). Theoretical studies have investigated the excitation of the wave, its global-scale structure and its interaction with other waves and tides (e.g., Norton and Thuburn, 1996; Palo et al., 1999; Jacobi et al., 2006; Salby and Callaghan, 2008).

These studies have led to an overall understanding of the general characteristics of the 2-day wave. Observations of the 2-day wave have revealed that its amplitude maximises at middle to low latitudes in summer (e.g., Wu et al., 1996; Limpasuvan and Wu, 2003; Merzlyakov et al., 2004; Limpasuvan et al., 2005). At middle and low latitudes, the wave is composed primarily of westward-propagating zonal wavenumbers 3 and 4 (hereafter W3 and W4). The wave maximises in mid to late summer at mesopause heights

Published by Copernicus Publications on behalf of the European Geosciences Union. 
and attains maximum amplitude between $90-95 \mathrm{~km}$ in both hemispheres. At these latitudes, the amplitude maximum in the Southern Hemisphere exceeds that of the Northern Hemisphere. The Southern Hemisphere wave is primarily a W3 wave, while the Northern Hemisphere wave is a mixture of $\mathrm{W} 2, \mathrm{~W} 3$ and $\mathrm{W} 4$. The wave period also varies between the two hemispheres. In the Southern Hemisphere at low to middle latitudes the wave period is often observed to be very close to 2 days (e.g., Craig et al., 1980; Wu et al., 1996) However, at high southern latitudes the period has been observed to be slightly longer, e.g., in the range $50-53 \mathrm{~h}$ (e.g., Baumgaertner et al., 2008). In the Northern Hemisphere the wave period is observed to range between about 1.8 and 2.2 days. In both hemispheres the vertical wavelength is usually observed to be very large (larger than $\sim 70 \mathrm{~km}$ ). Further, note that a recent study by Palo et al. (2007) suggested that non-linear interaction between the summertime 2-day wave and the migrating diurnal tide might generate a wavenumber 2 eastward propagating 2-day wave (hereafter E2) which would occur simultaneously with the westward propagating modes.

Two mechanisms have been proposed for the excitation of the westward-propagating 2-day wave in the middle atmosphere. The first is that the 2-day wave is a manifestation of the $(3,0)$ Rossby-gravity normal mode (Salby, 1981). The second is that the 2-day wave arises from a baroclinic instability of the summer mesospheric jet (Plumb, 1983). This latter mechanism was further developed by Pfister (1985) in a two-dimensional stability analysis. Theoretical and observational studies have supported both the normal-mode and instability interpretations, suggesting that the excitation mechanism of the 2-day wave may actually be a combination of the two. For instance, the theoretical study of Salby and Callaghan (2001) suggested that under solstice conditions the Rossby-gravity mode amplifies through sympathetic interaction with the summertime mean flow. This instability forcing appears to have little effect on the period or structure of the 2-day wave.

In contrast to the situation at middle and low latitudes, there have been relatively few studies of the 2-day wave at polar latitudes in the MLT, although 2-day waves have been reported in the winter polar stratosphere region (e.g., Prata, 1984; Coy et al 2003; Lait and Stanford, 1988). Recent studies made using ground-based radars have investigated the summertime mesospheric polar 2-day wave and have also revealed the existence of strong 2-day wave activity around the winter solstice at high latitudes (Nozawa et al., 2003a, b; Manson et al., 2004; Merzlyakov et al., 2004; Riggin et al., 2004; Nozawa et al., 2005; Palo et al., 2007; Baumgaertner et al., 2008; Sandford et al., 2008). Nozawa et al. (2003a) presented a climatology of the 2-day wave in the Arctic based on three years of observations at heights of 70-91 km made by an MF radar at Troms $\varnothing\left(69.6^{\circ} \mathrm{N}, 19.2^{\circ} \mathrm{E}\right)$. They observed 2-day wave activity in both summer and winter. Nozawa et al. (2003b) further investigated the characteristics of the 2-day wave at Troms $\varnothing\left(69.6^{\circ} \mathrm{N}, 19.2^{\circ} \mathrm{E}\right)$ and Poker Flat $\left(65.2^{\circ} \mathrm{N}, 147.6^{\circ} \mathrm{W}\right)$. They suggested that zonal wavenumbers 2 and 4 occur more frequently than zonal wavenumber 3 and that the wintertime 2-day wave might actually be an E2 oscillation. Manson et al. (2004) presented observations of the 2-day wave for one year using MF radars at Troms $\emptyset$ $\left(69.6^{\circ} \mathrm{N}, 19.2^{\circ} \mathrm{E}\right)$, Andenes $\mathrm{MF}$ radar $\left(69^{\circ} \mathrm{N}, 16^{\circ} \mathrm{E}\right)$, and meteor radar at Esrange $\left(68^{\circ} \mathrm{N}, 21^{\circ} \mathrm{E}\right)$. Again, significant wave activity was observed in winter as well as in summer. This strong winter activity is not observed at low or middle latitudes.

There have been very few studies of the Antarctic 2-day wave. Phillips (1989) observed the 2-day wave over Mawson, Antarctica $\left(67^{\circ} \mathrm{S}, 63^{\circ} \mathrm{E}\right)$ and Adelaide, Australia $\left(35^{\circ} \mathrm{S}\right.$, $138^{\circ} \mathrm{E}$ ). Baumgaertner et al. (2008) reported 2-day waves in the Antarctic at heights up to $95 \mathrm{~km}$ measured by MF radars at Scott Base $\left(78^{\circ} \mathrm{S}, 167^{\circ} \mathrm{E}\right)$, Davis $\left(69^{\circ} \mathrm{S}, 78^{\circ} \mathrm{E}\right)$, and Rothera $\left(68^{\circ} \mathrm{S}, 68^{\circ} \mathrm{W}\right)$. Again, wave activity was evident in summer and winter. Sandford et al. (2008) used geopotential height data from the Aura satellite to investigate the zonal structure of the wintertime 2-day wave and confirmed that it is an E2 oscillation, probably originating on the poleward flank of the stratospheric polar vortex and propagating up into the MLT.

In this study we present simultaneous observations of summertime and wintertime polar 2-day waves in the MLT region. The observations were made using identical meteor radars at conjugate geographical latitudes and so extend the earlier studies described above. Horizontal wind data are used to establish the general characteristics of the waves in the Antarctic and Arctic MLT region at heights of $\sim 80$ $100 \mathrm{~km}$. Representative climatologies of the summertime and wintertime waves are determined from multiple years worth of data (2005-2008 at Rothera and 1999-2008 at Esrange). Inter-annual variability is investigated. A key focus of the work is to quantify differences between the 2-day waves of the Antarctic and Arctic regions and investigate interactions of the waves with the general circulation.

\section{Data and analysis}

The data analysed in this paper were obtained from two meteor radars located at Rothera $\left(68^{\circ} \mathrm{S}, 68^{\circ} \mathrm{W}\right)$ in the Antarctic and Esrange $\left(68^{\circ} \mathrm{N}, 21^{\circ} \mathrm{E}\right)$ in Arctic Sweden. The Rothera radar has been in operation since February 2005 and the Esrange radar since October 1999. Both radars have been in continuous operation for most of the time since these dates.

Both radars are commercially produced SKiYMET VHF systems that operate in an "all-sky" configuration with radiated power being largely independent of azimuth. The radars have height and time resolutions of about $1 \mathrm{~km}$ and about $1 \mathrm{~h}$, respectively. See Hocking et al. (2001) and Mitchell et al. (2002) for details. The radars operate continuously, generating hourly values of zonal and meridional winds at heights 
of $\sim 80-100 \mathrm{~km}$. This height range is split into six independent height-gates with depths of 5, 3, 3, 3, 3, $5 \mathrm{~km}$. However, the vertical distribution of meteor echoes is strongly peaked at a height of $\sim 90 \mathrm{~km}$ and the meteor counts decrease above and below this height. To allow for this, in each heightgate the average meteor echo height is calculated from all the meteors within that gate. This yields heights of 80.8 , 84.7, 87.5, 90.4, 93.3 and $97.1 \mathrm{~km}$, as the mean heights of all the meteor echoes falling within each of the above six height gates. There is very little variation in the distribution of echo heights with time and so these values are used throughout the data set

For each month of data a variance value was calculated from the bandpassed horizontal winds in each height gate. The winds were bandpassed between 1.6 and 2.8 days. This variance is taken as a proxy for the activity of the 2-day waves in each height gate for the month in question. This was done for both zonal and meridional winds. Variance is a useful quantity because it is proportional to wave kinetic energy density per unit mass. However, it is also useful to relate this to wave amplitudes. For a sine wave, wave amplitude is equal to the square root of two times the variance. This means that variances of $20,60,100$ and $140 \mathrm{~m}^{2} \mathrm{~s}^{-2}$ correspond to wave amplitudes of $6.3,11.0,14.1$ and $16.7 \mathrm{~ms}^{-1}$. Note that there may be significant short-term variability of the 2-day wave within each month. The monthly variance (and its equivalent amplitude) represents the average level of wave activity for that month.

\section{Results}

\subsection{General characteristics of the polar 2-day waves}

The occurrence of 2-day waves in the MLT region observed by the radars can be investigated by the use of spectral analysis. Figure 1 presents a wavelet analysis of meridional winds over Rothera and Esrange for the years 2005 to 2008. These years are chosen because they are the ones for which simultaneous observations were made over both Rothera and Esrange. A Morlet wavelet was used with 6 cycles of the wave contained within a Gaussian envelope. This wavelet was chosen because it has a similar morphology to the episodes of planetary-wave activity often reported in the MLT. The results are for a height of $93.3 \mathrm{~km}$. The figure reveals that there is a rich field of planetary-wave activity over both Rothera and Esrange. Planetary-wave activity can be seen to occur in strong intermittent bursts and to have wave periods from less than 2 days to more than 10 days. If we consider waves with periods near 2 days, it can be seen that the bursts are of relatively short duration, often lasting no more than 10 days or so. Significant wave amplitude is present at wave periods from about 1.5 to near 3 days. Wave activity appears to be strongest around the summer and winter solstices and signif- a) ROTHERA MERIDIONAL 2005

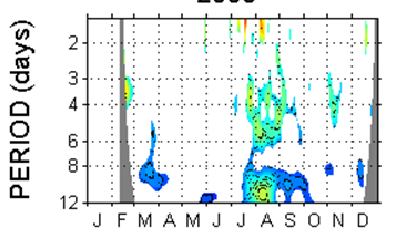

2006

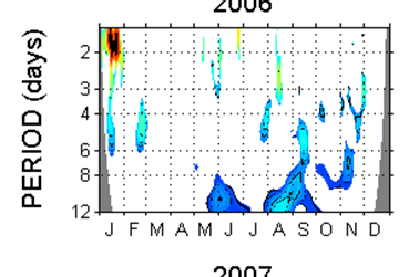

2007

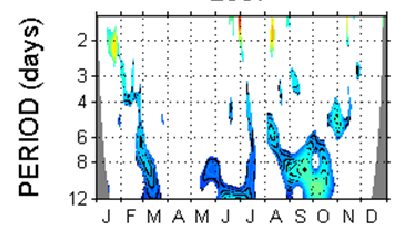

2008
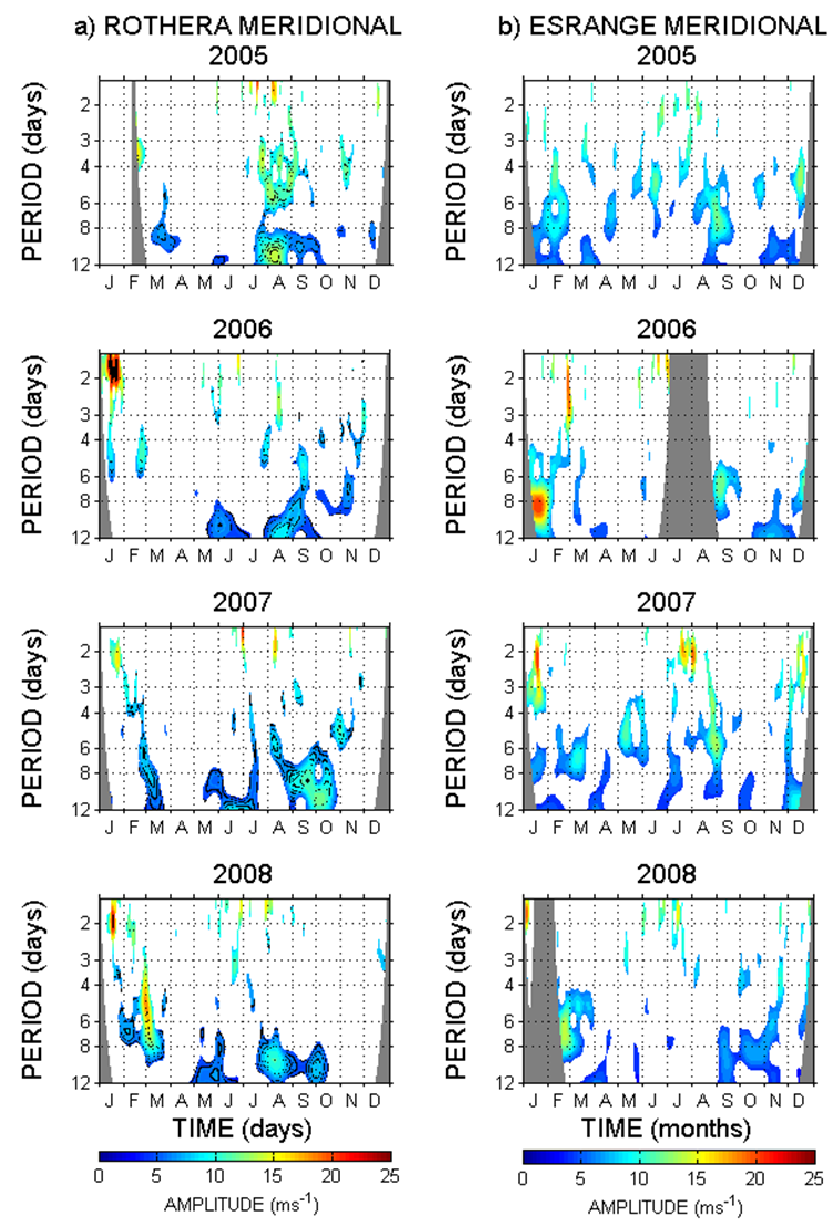

2007
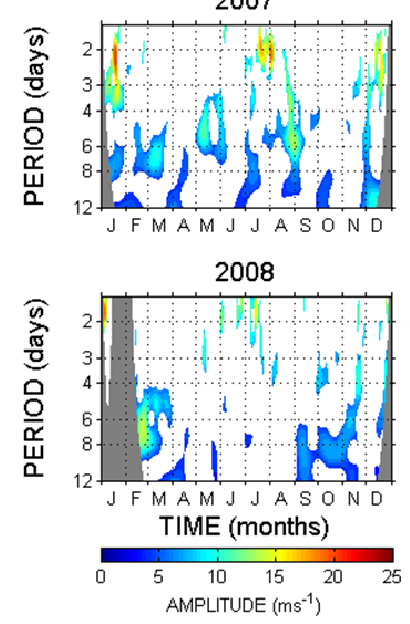

Fig. 1. Wavelet analysis of meridional winds as a function of time at a height of $\sim 93 \mathrm{~km}$ (a) over Rothera in 2006, (b) over Esrange in 2007. The signal is only plotted above the $95 \%$ confidence level.

icantly weaker around the equinoxes. We will describe these waves with period near 2 days as "2-day waves".

To determine the period of the wave in different seasons, periods between 1.7-2.5 days were least squares fitted to zonal and meridional winds in a 12-day window. The period of the fitted wave was moved in $1 \mathrm{~h}$ steps from $40 \mathrm{~h}(1.7$ days) to $60 \mathrm{~h}$ ( 2.5 days). The wave period at which maximum amplitude occurred was recorded and taken to be the period of the 2-day wave in that window. This window was then incremented through the time series in steps of 3 days. This analysis was applied to the summer (June - August) and winter (December-January) months for each year in both hemispheres and for all height gates. The wave period determined from each fit was then averaged over the season to yield a seasonally-averaged wave period for the 2-day wave. A threshold wave amplitude of $10 \mathrm{~ms}^{-1}$ was used as a cut off in this seasonal averaging so that the wave period was only determined from intervals of strong wave activity. 

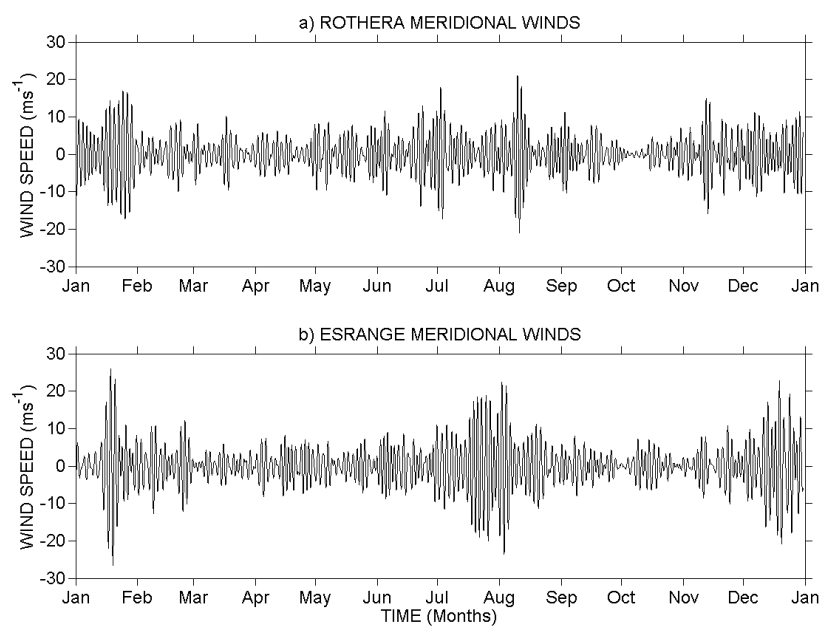

Fig. 2. Bandpassed meridional winds as a function of time at a height of $\sim 93 \mathrm{~km}$, for 2007, (a) over Rothera, (b) over Esrange. The data have been bandpassed between periods of 1.6 and 2.8 days.

The results of this analysis suggest that in Antarctic summer, the average wave period is $51.1 \mathrm{~h}$ (2.13 days). In Arctic summer the average wave period is $54.7 \mathrm{~h}$ ( 2.28 days). In winter, the wave period maximises with a period of $52.7 \mathrm{~h}$ (2.20 days) in the Antarctic and $54.5 \mathrm{~h}$ (2.27 days) in the Arctic. The uncertainty in these wave periods is $\sim 1 \mathrm{~h}$. These results are in general agreement with the observations described in Sect. 1.

To examine the 2-day waves in more detail, the wind time series were bandpassed as described in Sect. 2. The filter was an elliptical type with the $99 \%$ high/low cut-off frequencies corresponding to periods of 1.6 and 2.8 days. We assume that wave activity within this period band is dominated by the 2day waves of interest (note that at the latitude of Rothera and Esrange the inertial period is approximately 0.54 days and so there will be no significant gravity-wave activity within the frequency band selected for the filter).

Figure 2 presents the results of this analysis in the case of meridional winds recorded over Rothera and Esrange, respectively, in 2007. The figure shows that wave activity is present throughout the year in this period range, but that strong bursts of wave activity occur only in winter and in late summer. For example, over Rothera amplitudes exceed $10 \mathrm{~ms}^{-1}$ in winter (June-August) and in summer (December-January). Similarly, over Esrange wave amplitudes exceed $10 \mathrm{~ms}^{-1}$ in winter (December-January) and in summer (July-August). The zonal amplitudes (not shown) reveal a similar pattern of behaviour, although the zonal amplitudes are smaller in the Arctic summer.

We can quantify the duration of bursts of activity of the 2-day wave by noting the length of time a particular burst of activity has an amplitude above a particular threshold. If we consider a threshold amplitude of $10 \mathrm{~ms}^{-1}$, we find that in summer there were 26 separate bursts of wave activity with a) ROTHERA SUMMER 2006/2007

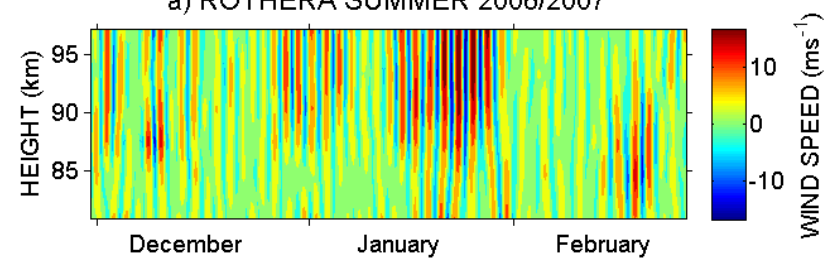

b) ESRANGE SUMMER 2007

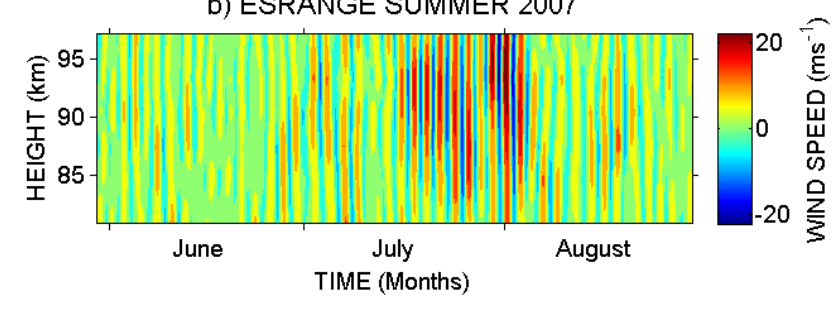

Fig. 3. Bandpassed meridional winds as a function of time and height during summertime 2007 , for heights of $\sim 80-97 \mathrm{~km}$, (a) over Rothera, (b) over Esrange. The data were bandpassed between periods of 1.6 and 2.8 days.

amplitude greater than this threshold in the 13 summer seasons observed (4 summers over Rothera and 9 over Esrange). Here we define summer as December, January and February (Rothera) and June, July and August (Esrange). In these 26 bursts, 8 had durations $<5$ days, 13 had durations of 5-10 days, 3 had durations of 10-15 days and only 2 had durations $>15$ days.

There were also 13 winter seasons observed with 20 separate bursts of wave activity in which amplitudes exceeded $10 \mathrm{~ms}^{-1}$. Here we define winter as June, July and August (Rothera) and December, January and February (Esrange). In these 20 winter bursts, 10 had durations $<5$ days, 6 had durations of 5-10 days, 2 had durations of 10-15 days and 2 had durations $>15$ days. This suggests that the bursts of wave activity are on average of longer duration in summer than in winter.

To investigate the vertical structure of the summer and winter waves, data from the six height gates were bandpassed as above and then used to produce time - height contours of zonal and meridional winds over each site. Figure 3 presents two examples of this analysis for periods of strong wave activity evident in Fig. 2. Figure 3a presents contours of the summertime meridional wind over Rothera in the Antarctic for 1 December 2006 to 28 February 2007. Figure 3b presents contours of the summertime meridional wind over Esrange for 1 June 2007 to 31 August 2007. These intervals are presented as being typical of summertime 2-day wave activity observed in bursts over these two sites. Several distinguishing characteristics are apparent from the examples, i) the wave activity occurs in strong bursts with duration of 10 to 20 days, although wave activity is present throughout the whole height-time interval, ii) the phase fronts of the wave 
a) ROTHERA WINTER 2007

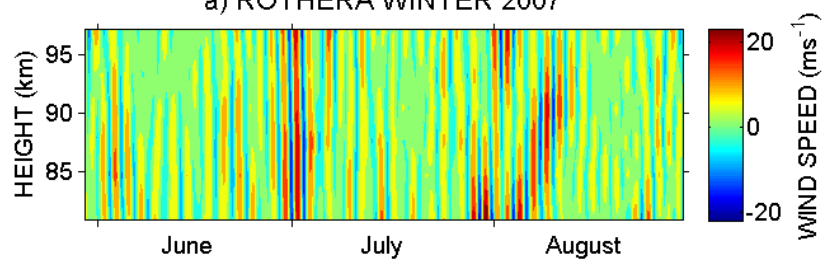

b) ESRANGE WINTER 2006/2007

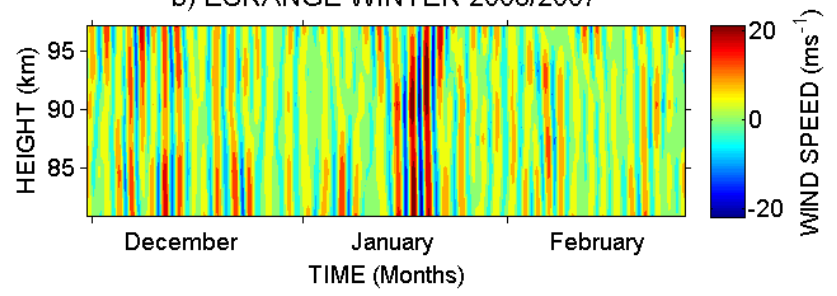

Fig. 4. Bandpassed meridional winds as a function of time and height during wintertime 2007, for heights of $\sim 80-97 \mathrm{~km}$, (a) over Rothera, (b) over Esrange. The data were bandpassed between periods of 1.6 and 2.8 days.

are effectively vertical, implying a long vertical wavelength, iii) in the Antarctic the wave only reaches large amplitudes $\left(>10 \mathrm{~ms}^{-1}\right)$ at heights above about $90 \mathrm{~km}$. In the Arctic the wave maximises at heights of $90-95 \mathrm{~km}$ and decays above this height.

Figure 4 presents similar examples of this analysis for data representative of the winter season. Figure 4 a presents contours of the wintertime meridional wind over Rothera for 1 June 2007 to 31 August 2007. Figure 4b presents contours of the wintertime meridional wind over Esrange for 1 December 2006 to 28 February 2007. These intervals are again presented as being typical of wintertime 2-day wave activity. Several distinguishing characteristics are again apparent from the figures, i) the wave activity again occurs in bursts, although there is a suggestion that the bursts are of shorter duration than is the case in the summertime, ii) the phase fronts are again effectively vertical, implying a long vertical wavelength, iii) in contrast to the summertime wave, the wave activity occurs across the whole height range observed and does not seem to maximise in a particular height range.

\subsection{Climatology of the polar 2-day waves}

From the results presented in the previous Section it is apparent that there is a seasonal cycle in the 2-day wave activity. To investigate this further, Fig. 5 presents time-height contours of monthly variance at heights of $\sim 80-100 \mathrm{~km}$ for zonal and meridional components measured over Rothera from April 2005 to December 2008 (calculated as in Sect. 2). Indicated on each figure as open contours are the monthlymean zonal winds for each year. From the figure it can be seen that there is a seasonal cycle in 2-day wave activity with a maximum in mid to late summer (December-February), a secondary maximum in winter (reaching largest variances in June-August) and equinoctial minima. These maxima correspond to the events described in Sect. 3.1. As suggested by the bandpassed results of Fig. 3, the summertime wave reaches largest variances at heights above $\sim 90-95 \mathrm{~km}$. For instance, zonal monthly variances exceed $100 \mathrm{~m}^{2} \mathrm{~s}^{-2}$ in January 2006, 2007 and 2008, corresponding to monthly-mean amplitudes of $>14 \mathrm{~ms}^{-1}$. In contrast, the wintertime wave can reach large variances across the entire height range observed. A considerable degree of inter-annual variability is also apparent. For example, the summertime 2-day wave is significantly stronger in 2006 compared to 2007 or 2008. This is particularly noticeable in the meridional component. However, in summer there is a clear tendency for the wave activity to be strong only in the regions of eastward winds above the zero-wind line. The wintertime 2-day wave also exhibits significant inter-annual variability.

Figure 6 presents a similar analysis applied to data from Esrange. The seasonal behaviour is generally similar to that observed over Rothera. Again, the summertime 2-day wave tends to maximise at heights above $\sim 90 \mathrm{~km}$, above the zerowind line, and the wintertime 2-day wave is present across the height range observed. Inter-annual variability is also very strong.

One difference evident between the results from Rothera and Esrange is that over Rothera the summertime 2-day wave has larger variances in the zonal component than in the meridional, whereas over Esrange the meridional variances are larger than the zonal variances.

To provide a clearer understanding of the seasonal behaviour of the 2-day wave, a composite-year analysis (i.e. a superposed-epoch or average-year analysis) was carried out using all available data. The monthly variance data have a log-normal distribution and so the composite year cannot be produced by simply averaging the monthly variances in a particular height gate over all the years available. Instead, the variance was calculated for a given month and height gate by constructing a continuous time series of bandpassed winds for that height gate and month using data from all years. A variance was then calculated for this single time series and the procedure repeated for all other height gates and months. Figure 7a presents time-height contours of a composite-year analysis at heights of $\sim 80-100 \mathrm{~km}$ for the meridional component of winds over Rothera. The monthly-mean zonal winds were similarly averaged. Contours of these mean zonal winds are also plotted on the figure as lines. Figure $7 \mathrm{~b}$ presents a similar analysis of the zonal component of the 2day wave. Again, the monthly mean zonal winds are also plotted for comparison.

It can be seen from the figures that over Rothera the summertime wave has a much larger variance than the wintertime wave. The summertime wave reaches variances above $160 \mathrm{~m}^{2} \mathrm{~s}^{-2}$, at heights above $\sim 90 \mathrm{~km}$ in the zonal component. In fact, the summertime wave variance maximises just above the zero-wind line in both components. In contrast the 
6382 V. M. Tunbridge and N. J. Mitchell: The two-day wave in the Antarctic and Arctic mesosphere and lower thermosphere
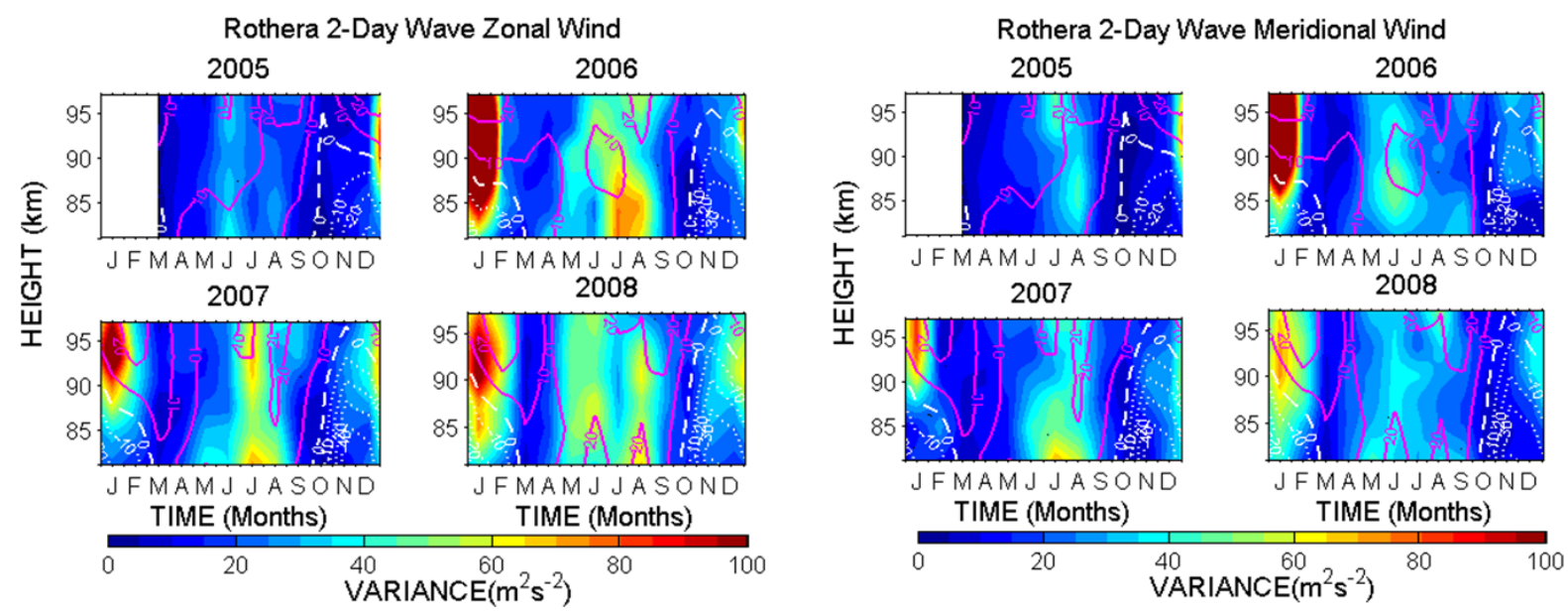

Fig. 5. Time-height contours of the monthly variance of bandpassed horizontal winds over Rothera in the Antarctic between April 2005 and December 2008. The bandpass is between periods of 1.6 and 2.8 days. Also plotted are monthly mean zonal winds (open contours). The zero-wind contour is indicated by the heavy dashed white line.
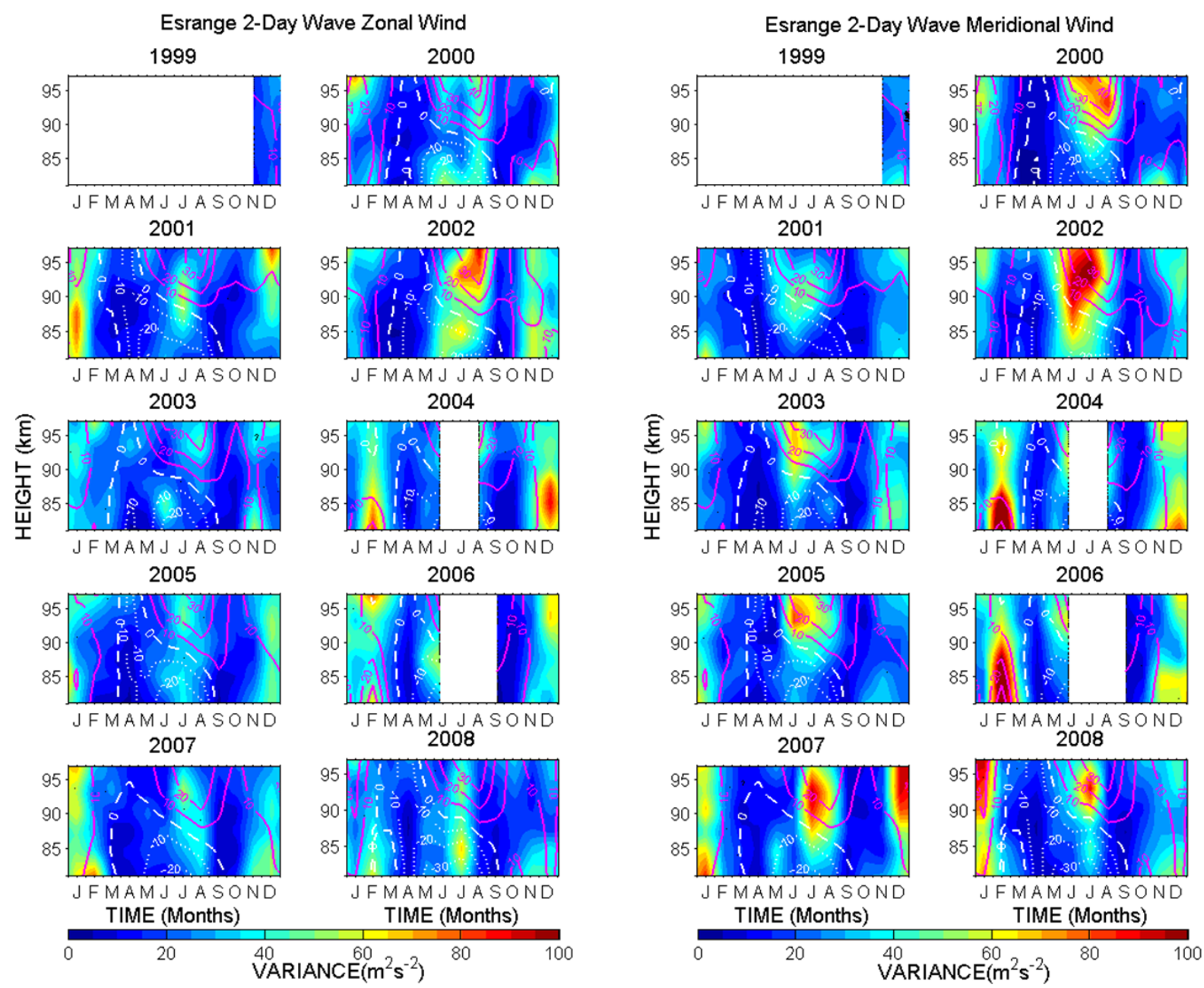

Fig. 6. Time-height contours of the monthly variance of bandpassed horizontal winds over Esrange in the Arctic between October 1999 and December 2008. The bandpass is between periods of 1.6 and 2.8 days. Also plotted are monthly mean zonal winds (open contours). The zero-wind contour is indicated by the heavy dashed white line. 
a) ROTHERA MERIDIONAL

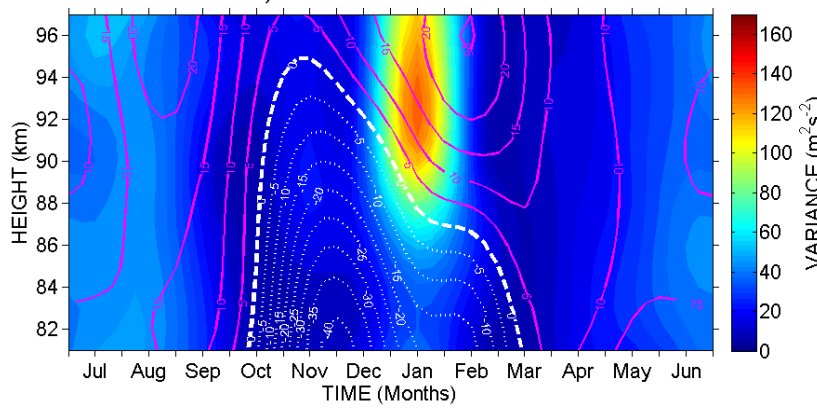

b) ROTHERA ZONAL

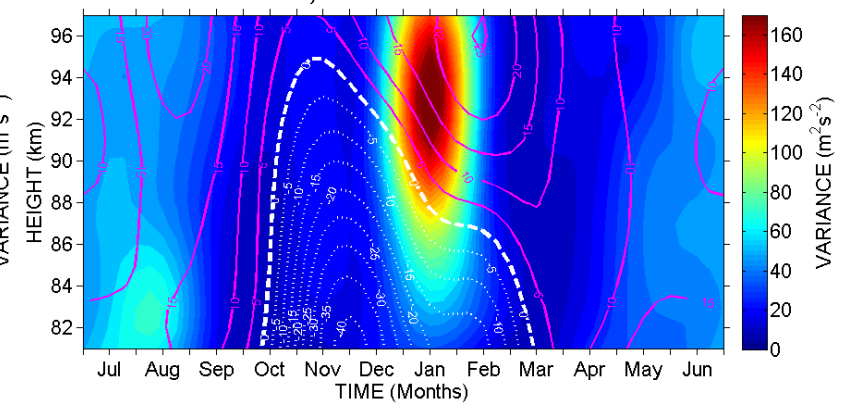

Fig. 7. A composite-year analysis of the Rothera (Antarctic) variance data from Fig. 5 for (a) the meridional component and (b) the zonal component (filled colour contours). Also plotted are monthly mean zonal winds (open contours). The zero-wind contour is indicated by the heavy dashed white line. Note that the time axis is arranged so as to allow easy comparison with Fig. 8 (i.e. summer in the centre).

a) ESRANGE MERIDIONAL

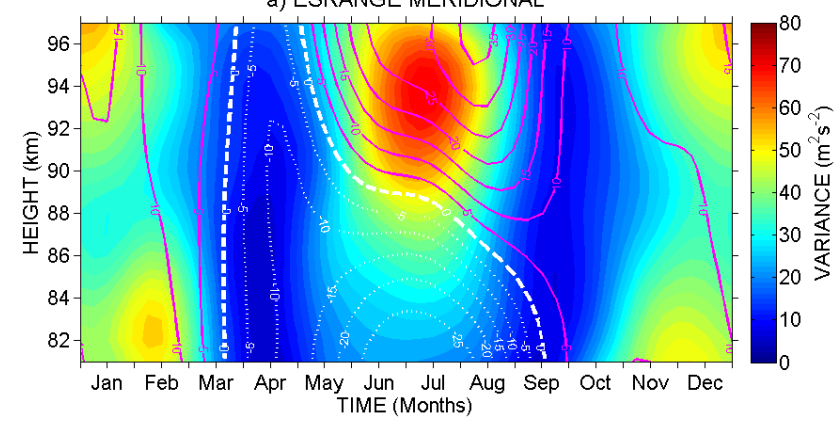

b) ESRANGE ZONAL

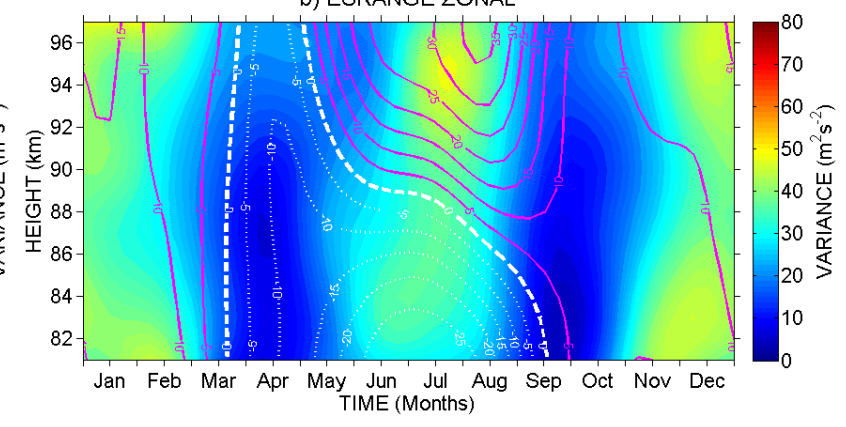

Fig. 8. A composite-year analysis of the Esrange (Arctic) variance data from Fig. 6 for (a) the meridional component and (b) the zonal component (filled colour contours). Also plotted are monthly mean zonal winds (open contours). The zero-wind contour is indicated by the heavy dashed white line.

wintertime wave is generally smaller than $60 \mathrm{~m}^{2} \mathrm{~s}^{-2}$ at most heights.

Figure 8 presents a similar composite-year analysis for the data from Esrange. As in Fig. 7, contours of mean zonal winds are plotted on the figure as lines. The results from Esrange are generally similar to those from Rothera. Again the summertime wave has a larger maximum variance than the wintertime wave and maximises just above the zerowind line. The summertime wave reaches a maximum of $\sim 60 \mathrm{~m}^{2} \mathrm{~s}^{-2}$ at a height of $\sim 93 \mathrm{~km}$ in the meridional component. The zonal component is rather weaker, with a maximum of $\sim 50 \mathrm{~m}^{2} \mathrm{~s}^{-2}$. The wintertime wave has a variance at most heights of about $40 \mathrm{~m}^{2} \mathrm{~s}^{-2}$, with a minimum at about $88-90 \mathrm{~km}$ in both zonal and meridional components.

\subsection{Antarctic/Arctic comparisons}

We will now compare and contrast the climatology of summertime and wintertime 2-day waves in the Antarctic and Arctic.
Firstly, we will consider the summertime 2-day wave. From Figs. 7 and 8, it can be seen that there are a number of key similarities and differences between the 2-day wave of the two polar regions. These are:

1. The maximum variance of the wave is larger in the Antarctic than the Arctic. This is true in both the zonal and meridional components. For example, in the Antarctic the summertime wave monthly variance reaches values larger than $160 \mathrm{~m}^{2} \mathrm{~s}^{-2}$, whereas in the Arctic the equivalent value is only about $60 \mathrm{~m}^{2} \mathrm{~s}^{-2}$.

2. The relative magnitude of the zonal and meridional components is different between the two hemispheres. In the Antarctic, the zonal component is larger than the meridional and the ratio of peak variance, zonal $/$ meridional, is about 1.3 at a height of about $93 \mathrm{~km}$ in January. In contrast, in the Arctic the meridional component is larger than the zonal and the ratio of peak variance, zonal/meridional, is about 0.7 at a height of about $93 \mathrm{~km}$ in July. 
6384 V. M. Tunbridge and N. J. Mitchell: The two-day wave in the Antarctic and Arctic mesosphere and lower thermosphere

a) MERIDIONAL VARIANCES

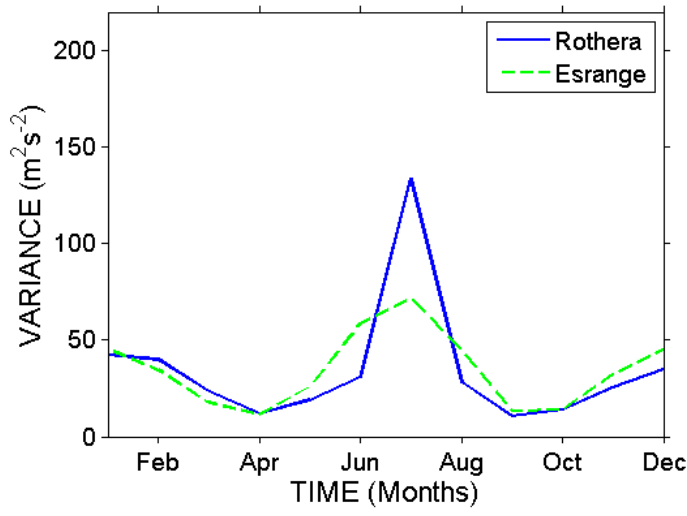

b) ZONAL VARIANCES

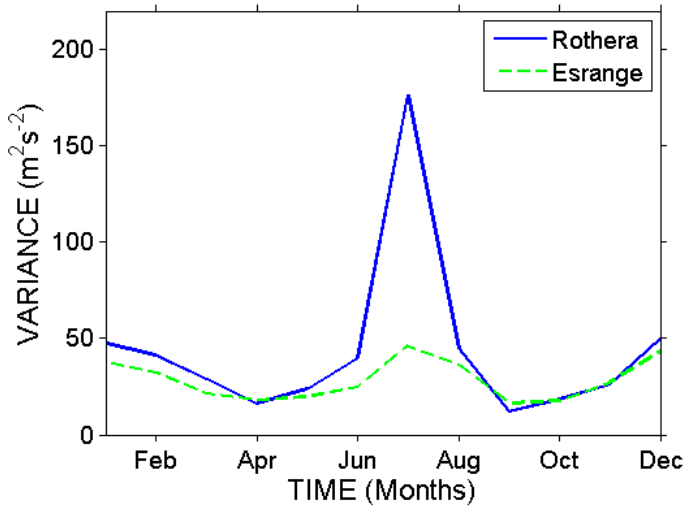

Fig. 9. A composite year analysis of variances at a height of $\sim 93 \mathrm{~km}$, corresponding to the data shown in Figs. 7 and 8 for (a) the meridional component and (b) the zonal component. Months are for Esrange, Rothera data shifted by 6 months to make seasons comparable.

3. In both hemispheres the summertime wave maximises at a height of about $93 \mathrm{~km}$. This is in the region of strongly sheared zonal flow associated with the summertime middle atmosphere zonal jet. The waves reach largest amplitudes above the zero-wind line, but are still detectable to the lowest heights observed.

4. The duration of occurrence of the 2-day wave appears to be shorter in the Antarctic than in the Arctic. In the Antarctic, strong wave activity lasts only a little longer than one month (January), but in the Arctic strong wave activity is evident for at least three months (JuneAugust). This appears to be connected to the duration of the strongly-sheared zonal flow occurring above the zero-wind line. In the Antarctic, such strong shear above the zero-wind line, with the zero-wind line at a height of about $90 \mathrm{~km}$ or below, only occurs in January. So although there is strong zonal wind shear in December, the zero-wind line occurs at heights above $95 \mathrm{~km}$ and there is no evidence of the wave having significant activity. In contrast, in the Arctic, strong zonal wind shears exist above the zero-wind line with the zerowind line being below about $90 \mathrm{~km}$ throughout JuneAugust. The wave is observed throughout this longer interval. However, because only three summer seasons of Antarctic observations are available these conclusions must be treated with some caution.

To investigate the duration of occurrence of the 2-day wave in more detail, Fig. 9a, b presents composite variances at a height of $\sim 93 \mathrm{~km}$. The variances calculated over Rothera were shifted by 6 months in order to make the seasons comparable, so the months used on the time axis are those at Esrange. Figure 9a presents the meridional mean monthly variances measured over Rothera and Esrange. Figure $9 \mathrm{~b}$ presents a similar analysis for the zonal component. It can be seen from the figures that the summertime wave activity over the Antarctic is significantly more intense in both components. However, in the meridional component the Antarctic wave activity appears to be shorter lived than that in the Arctic, although this may be influenced by the strong 2005/2006 summertime event since this is a mean taken from 3 years.

Secondly, we will consider the wintertime 2-day wave. From Figs. 7 and 8, it can be seen that there are again a number of key similarities and differences between the wintertime 2-day wave of the two polar regions. These are:

1. The variances appear to be very similar in both the Antarctic and Arctic. The mean variances in both hemispheres reach maximum values between $\sim 50$ $60 \mathrm{~m}^{2} \mathrm{~s}^{-2}$.

2. In both hemispheres the ratio of zonal to meridional variances is approximately one.

3. The wave is evident across the height range observed, but in both hemispheres has a minimum at heights between $\sim 88-90 \mathrm{~km}$ with maxima above and below this height.

4. In both hemispheres the duration of the wave appears to be very similar. The wave reaches largest variances (say, above $20 \mathrm{~m}^{2} \mathrm{~s}^{-2}$ ) in May-August over Rothera and November-February over Esrange.

To investigate further the differences in the 2-day wave between the Antarctic and Arctic, a ratio of the composite years of Figs. 7 and 8 was calculated. The composite monthly mean variances calculated over Rothera were shifted by 6 months in order to make the seasons comparable. Figure 10 presents time-height contours of these ratios. In the figure, the months used on the time axis correspond to the month at Esrange. Figure 10a presents the composite monthly mean variances for the meridional component of the 2-day wave 
V. M. Tunbridge and N. J. Mitchell: The two-day wave in the Antarctic and Arctic mesosphere and lower thermosphere 6385
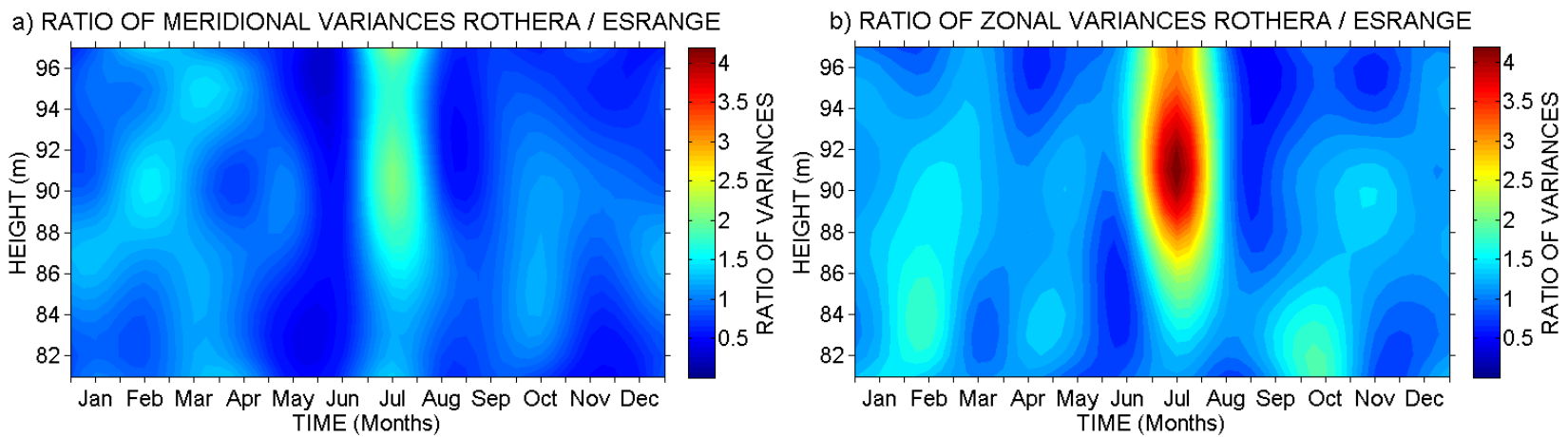

Fig. 10. A ratio of the composite year analyses from Figs. 7 and 8 for (a) the meridional component and (b) the zonal component. In each case the ratio is the variance at Rothera divided by the variance at Esrange. The months are for Esrange, Rothera data shifted by 6 months to make seasons comparable.

over Rothera divided by the equivalent variance from Esrange. Figure $10 \mathrm{~b}$ presents a similar analysis for the zonal component. Differences of the composite years of Figs. 7 and 8 were also calculated for both zonal and meridional components (not shown here). The differences calculated confirmed the results in Fig. 10.

The data presented in the figure show considerable interhemispheric differences between Rothera and Esrange. The summertime 2-day wave (June-August) is stronger over Rothera, in both the zonal and meridional components. The ratio reaches a maximum of just over 4 in the zonal component at heights of $\sim 90-94 \mathrm{~km}$, corresponding to larger wave amplitudes in the Antarctic. In contrast, in the meridional component, although the variances are larger over Rothera the ratio is only about 2.5 .

If we consider the wintertime 2-day wave, there is no clear tendency for larger variances over either polar region.

\section{Discussion}

Nozawa et al. (2003b) suggested that in the mesosphere and lower thermosphere the summertime 2-day wave and the wintertime 2-day wave are actually separate phenomena, the first being the familiar W2, W3, W4 propagating planetary waves and the latter being an E2 wave. Palo et al. (2007), Baumgaertner et al. (2008) and Sandford et al. (2008) used satellite observations to confirm this suggestion. Palo et al. (2007) suggested that E2 waves of this type are generated by non-linear interactions between the summertime 2-day wave and the migrating diurnal tide. Sandford et al. (2008) suggested that the wintertime E2 wave observed in the MLT is the mesospheric manifestation of a stratospheric wave proposed by Prata (1984) to originate on the poleward flank of the winter polar stratospheric vortex. Here we will discuss the summertime and wintertime waves in turn.
Firstly, we will consider the summertime 2-day wave. A number of observers have investigated the 2-day wave at mid-latitudes in the northern and Southern Hemispheres. The wave periods we observe are generally in agreement with those reported in other high latitude studies (e.g., Nozawa et al., 2003; Baumgaertner et al., 2008). These studies have revealed a general pattern in which the largest amplitudes occur in the Southern Hemisphere (e.g., Craig et al., 1980; Rodgers and Prata, 1981; Craig et al., 1983; Limpasuvan and $\mathrm{Wu}, 2003)$. Our observations suggest that the larger Southern Hemisphere amplitudes persist to high latitudes and are clearly observed in the polar regions. This inter-hemispheric difference in amplitude is probably due to the different wavenumber components comprising the 2-day wave in the two hemispheres. In particular, the Southern Hemisphere is known to be dominated by a W3 component, whereas the Northern Hemisphere is known to have significant additional contributions from the W2 and W4 components (e.g., Meek et al., 1996; Norton and Thuburn, 1996; Lieberman, 1999; Limpasuvan and Wu, 2003; Pancheva et al., 2004).

Our observations also suggest that the average duration of 2-day wave activity is shorter in the Antarctic than the Arctic, although the Antarctic wave can reach larger amplitudes. An explanation for this behaviour might be as follows. The major W3 component of the 2-day wave is believed to have the character of the Rossby $(3,0)$ normal mode, but can be excited by instabilities associated with the summertime mesospheric westward jet (e.g., Fritts et al., 1999; Lieberman, 1999; Salby and Callaghan, 2001; Rojas and Norton, 2007). We thus might expect to find strongest wave activity at times when there is strong shear in the summertime mesospheric jet.

However, the wave propagation is constrained by wave/mean-flow interactions as outlined by the CharneyDrazin theorem. Thus it can only propagate within a particular range of zonal wind speeds. The Charney-Drazin theorem 
can be approximated as allowing propagation only for zonal mean wind speeds, $0<\bar{u}-c_{x}<u_{c}$, where $\bar{u}$ is the zonal mean wind, $c_{x}$ is the zonal phase speed of the planetary wave which is $\sim-28 \mathrm{~ms}^{-1}$ for a 2 -day W3 wave at a latitude of $68^{\circ}$, where the minus sign indicates westward propagation and $u_{c}$ is the Rossby critical velocity (Charney and Drazin, 1961). This means that the wave should only be able to propagate in westward zonal wind speeds above $-28 \mathrm{~ms}^{-1}$ (i.e. the wave cannot propagate through the strongly westward flow of the summertime middle-atmosphere jet). Similarly, a 2-day W4 wave at these latitudes should only be able to propagate in zonal winds above $-21 \mathrm{~ms}^{-1}$.

This application of Charney-Drazin theorem is subject to two qualifications. The first is that the simple theory quoted above is an approximation. Thus as noted by Luo et al. (2002), in the real atmosphere, weak wave activity may be observed outside of the regions defined by the theorem. The second qualification is that our results are presented as monthly mean winds and monthly variances. This means that in months where the average wind speed is outside the range specified by the theorem, there may still be episodes within that month where the wind speed does for a time fall within the range specified and so allowed the wave to propagate.

Because the zero-wind line is higher in the early months of the summer in the Antarctic, compared to the Arctic (at least in the years observed), the zonal winds are not strongly eastwards enough in the height range observed to allow the wave to propagate in the Antarctic during these early summer months. For example, over Rothera in November and December the zonal winds are almost entirely westward, whereas in the corresponding months in the Arctic (May and June) the winds become increasingly eastward above about $90 \mathrm{~km}$ (see Figs. 7 and 8). The summertime 2-day wave is thus largely absent in early Antarctic summer, but is present in early Arctic summer, leading to a reduced overall duration of occurrence in the Antarctic.

Secondly, we will consider the wintertime 2-day wave. In contrast to the summertime situation, the wintertime wave appears to have relatively small inter-hemispheric differences. In both the Antarctic and Arctic the seasonal climatology appears to be similar and the ratio of zonal to meridional variances is on average close to 1 . The wave is present throughout the height range observed in both hemispheres and has a smaller maximum variance (i.e., smaller amplitude) than the summertime wave in the climatological average.

In both hemispheres, the wintertime wave variance has a minimum at a height of $\sim 88-90 \mathrm{~km}$. This behaviour was also reported by Nozawa et al. (2005), where it was suggested that the secondary maxima in the wintertime 2-day wave amplitudes may be due to nonlinear coupling process between the 2-day wave and other waves/tides for example, the 24 and $12 \mathrm{~h}$ tides.

The wave was present in all the winters observed in both hemispheres and so seems to be a persistent feature of the wintertime polar mesosphere and lower thermosphere. Satellite observations have revealed this to be an E2 wave possibly originating in the lower polar stratosphere (Baumgaertner et al., 2008; Sandford et al., 2008) or generating by non-linear interactions (Palo et al., 2007). Our observations show that despite the well known differences between the Antarctic and Arctic lower stratosphere, at MLT heights there is surprisingly little inter-hemispheric difference in the character of the wintertime 2-day wave.

The seasonal behaviour of this wintertime wave suggests it interacts with the mean winds. For an E2 2-day wave at $68^{\circ}$ latitude, the zonal phase speed will be about $+43.6 \mathrm{~ms}^{-1}$. The wave will thus only be able to propagate in regions where the zonal wind speed is greater than this value. However, in our observations, significant wave activity is evident at times when the monthly-mean wind is smaller than this value. For instance, significant wave activity is observed during winter with monthly-mean zonal winds as small as $+20 \mathrm{~ms}^{-1}$. However, unlike the case with the summertime wave, this wintertime wave will have been able to propagate through the strongly eastward winds of the middleatmosphere jet to the heights where it is observed.

\section{Conclusions}

In this paper we have presented climatologies of the 2day wave at Antarctic and Arctic latitudes. These were constructed from data recorded using identical meteor radars situated at the conjugate geographical latitudes of Rothera, $\left(68^{\circ} \mathrm{S}, 68^{\circ} \mathrm{W}\right)$ and Esrange $\left(68^{\circ} \mathrm{N}, 21^{\circ} \mathrm{E}\right)$. Interhemispheric comparisons can therefore be made free from the biases that might affect measurements if made by different techniques, such as comparisons between meteor and MF radars. This allows a robust assessment of inter-hemispheric differences between the two polar regions. The observations reveal two distinctly different waves in summer and winter in both hemispheres. We suggest that the summertime wave is the polar manifestation of the classic mid-latitude W3 and W4 2-day wave. We suggest that the wintertime wave is the polar E2 wave reported in the satellite observations described in Sect. 1.

In summer, the 2-day wave was observed in each year. A considerable degree of inter-annual variability was observed in both hemispheres. The climatological mean reveals that the wave amplitude is, on average, larger in the Antarctic than the Arctic. In the Antarctic the zonal component of the wave is larger than the meridional (at least in the three years observed). This is in contrast to the Arctic where the meridional component dominates. However, the duration of strong wave activity in the Antarctic is usually shorter than in the Arctic. This shorter Antarctic duration may be due to the shorter interval of time during which a strong shear exists in the eastward zonal flow above the zero-wind line. The different durations of occurrence of the 2-day wave would thus 
be a consequence of the differences in the background flow of the two polar regions.

The wintertime 2-day wave is also a persistent feature of the polar MLT. It occurs each year. The variance (and thus amplitude) of the wintertime wave is generally smaller than the summertime wave in both the Antarctic and Arctic. The meridional and zonal components have approximately equal variances. There is clear inter-annual variation in the monthly wave variance but little variation in the months during which the wave occurs. Our observations show that the observed characteristics of the 2-day MLT wintertime wave are very similar in both hemispheres. From this we conclude that it is the same type of wave being observed in the Antarctic and Arctic (the E2 described above). This similarity in behavior of the Antarctic and Arctic wintertime wave occurs despite the significant inter-hemispheric differences known to exist in the lower stratosphere.

Edited by: W. Ward

\section{References}

Baumgaertner, A. J. G., McDonald, A. J., Hibbins, R. E., Fritts, D. C., Murphy, D. J., and Vincent, R. A.: Short-period planetary waves in the Antarctic middle atmosphere, J. Atmos. Sol.-Terr. Phy., 70, 1336-1350, doi:10.1016/j.jastp.2008.04.007, 2008.

Charney, J. G. and Drazin, P. G.: Propagation of Planetary-Scale Disturbances from the Lower into the Upper Atmosphere, J. Geophys. Res.-Atmos., 66, 83-109, doi:10.1029/JZ066i001p00083, 1961.

Coy, L., Stajner, I., DaSilva, A. M., Joiner, J., Rood, R. B., Pawson, S., and Lin, S. J.: High-frequency planetary waves in the polar middle atmosphere as seen in a data assimilation system, J. Atmos. Sci., 60, 2975-2992, 2003.

Craig, R. L., Vincent, R. A., Fraser, G. J., and Smith, M. J.: The Quasi 2-Day Wave in the Southern-Hemisphere Mesosphere, Nature, 287, 319-320, 1980.

Craig, R. L., Vincent, R. A., Kingsley, S. P., and Muller, H. G.: Simultaneous Observations of the Quasi 2-Day Wave in the Northern and Southern Hemispheres, J. Atmos. Terr. Phys., 45, 539$541,1983$.

Fritts, D. C., Isler, J. R., Lieberman, R. S., Burrage, M. D., Marsh, D. R., Nakamura, T. K., Tsuda, T., and Vincent, R. A.: Two-day wave structure and mean flow interactions observed by radar and High Resolution Doppler Imager, J. Geophys. Res.-Atmos., 104, 3953-3969, 1999.

Gurubaran, S., Sridharan, S., Ramkumar, T. K., and Rajaram, R.: The mesospheric quasi-2-day wave over Tirunelveli (8.7 degrees N), J. Atmos. Sol.-Terr. Phy., 63, 975-985, 2001.

Harris, T. J. and Vincent, R. A.: The Quasi-2-Day Wave Observed in the Equatorial Middle Atmosphere, J. Geophys. Res.-Atmos., 98, 10481-10490, 1993.

Hocking, W. K., Fuller, B., and Vandepeer, B.: Real-time determination of meteor-related parameters utilizing modern digital technology, J. Atmos. Sol.-Terr. Phy., 63, 155-169, 2001.

Jacobi, C., Schminder, R., and Kürschner, D.: The quasi 2-day wave as seen from D1 LF wind measurements over Central Europe (52 degrees N, 15 degrees E) at Collm, J. Atmos. Sol.-Terr. Phy., 59, 1277-1286, 1997.

Jacobi, C., Schminder, R., and Kürschner, D.: Non-linear interaction of the quasi 2-day wave and longterm oscillations in the summer midlatitude mesopause region as seen from LF D1 wind measurements over Central Europe (Collm, 52 degrees N, 15 degrees E), J. Atmos. Sol.-Terr. Phy., 60, 1175-1191, 1998.

Jacobi, C., Frohlich, K., and Pogoreltsev, A.: Quasi two-day-wave modulation of gravity wave flux and consequences for the planetary wave propagation in a simple circulation model, J. Atmos. Sol.-Terr. Phy., 68, 283-292, doi:10.1016/j.jastp.2005.01.017, 2006.

Lait, L. R. and Stanford, J. L.: Fast, Long-Lived Features in the Polar Stratosphere, J. Atmos. Sci., 45, 3800-3809, 1988.

Lieberman, R. S.: Eliassen-Palm fluxes of the 2-day wave, J. Atmos. Sci., 56, 2846-2861, 1999.

Limpasuvan, V. and Wu, D. L.: Two-day wave observations of UARS Microwave Limb Sounder mesospheric water vapor and temperature, J. Geophys. Res.-Atmos., 108(D10), 4307, doi:10.1029/2002jd002903, 2003.

Limpasuvan, V., Wu, D. L., Schwartz, M. J., Waters, J. W., Wu, Q., and Killeen, T. L.: The two-day wave in EOS MLS temperature and wind measurements during 2004-2005 winter, Geophys. Res. Lett., 32, L17809, doi:10.1029/2005g1023396, 2005.

Luo, Y., Manson, A. H., Meek, C. E., Meyer, C. K., Burrage, M. D., Fritts, D. C., Hall, C. M., Hocking, W. K., MacDougall, J., Riggin, D. M., and Vincent, R. A.: The 16-day planetary waves: multi-MF radar observations from the arctic to equator and comparisons with the HRDI measurements and the GSWM modelling results, Ann. Geophys., 20, 691-709, 2002, http://www.ann-geophys.net/20/691/2002/.

Manson, A. H., Meek, C. E., Hall, C.M., Nozawa, S., Mitchell, N.J., Pancheva, D., Singer, W., and Hoffmann, P.: Mesopause dynamics from the scandinavian triangle of radars within the PSMOSDATAR Project, Ann. Geophys., 22, 367-386, 2004, http://www.ann-geophys.net/22/367/2004/.

Meek, C. E., Manson, A. H., Franke, S. J., Singer, W., Hoffmann, P., Clark, R. R., Tsuda, T., Nakamura, T., Tsutsumi, M., Hagan, M., Fritts, D. C., Isler, J., and Portnyagin, Y. I.: Global study of Northern Hemisphere quasi-2-day wave events in recent summers near $90 \mathrm{~km}$ altitude, J. Atmos. and Terr. Phys., 58, 14011411, 1996.

Merzlyakov, E., Pancheva, D., Mitchell, N., Forbes, J. M., Portnyagin, Yu. I., Palo, S., Makarov, N., and Muller, H. G.: High- and mid-latitude quasi-2-day waves observed simultaneouslyby four meteor radars during summer 2000, Ann. Geophys., 22, 773788, 2004,

http://www.ann-geophys.net/22/773/2004/.

Mitchell, N. J., Pancheva, D., Middleton, H. R., and Hagan, M. E.: Mean winds and tides in the Arctic mesosphere and lower thermosphere, J. Geophys. Res.-Space, 107(A1), 1004, doi:10.1029/2001ja900127, 2002.

Muller, H. G.: Long-Period Meteor Wind Oscillations, Philosophical Transactions of the Royal Society of London Series aMathematical and Physical Sciences, 271, 585-598, 1972.

Norton, W. A. and Thuburn, J.: The two-day wave in a middle atmosphere GCM, Geophys. Res. Lett., 23, 2113-2116, 1996.

Nozawa, S., Imaida, S., Brekke, A., Hall, C. M., Manson, A., Meek, C., Oyama, S., Dobashi, K., and Fujii, R.: The quasi 2- 
6388 V. M. Tunbridge and N. J. Mitchell: The two-day wave in the Antarctic and Arctic mesosphere and lower thermosphere

day wave observed in the polar mesosphere, J. Geophys. Res.Atmos., 108(D2), 4039, doi:10.1029/2002jd002440, 2003a.

Nozawa, S., Iwahashi, H., Brekke, A., Hall, C. M., Meek, C., Manson, A., Oyama, S., Murayama, Y., and Fujii, R.: The quasi 2-day wave observed in the polar mesosphere: Comparison of the characteristics observed at Tromso and Poker Flat, J. Geophys. Res.Atmos., 108(D4), 4748, doi:10.1029/2002jd003221, 2003b.

Nozawa, S., Brekke, A., Maeda, S., Aso, T., Hall, C. M., Ogawa, Y., Buchert, S. C., Rottger, J., Richmond, A. D., Roble, R., and Fujii, R.: Mean winds, tides, and quasi-2 day wave in the polar lower thermosphere observed in European Incoherent Scatter (EISCAT) 8 day run data in November 2003, J. Geophys. Res.Space, 110, A12309, doi:10.1029/2005ja011128, 2005.

Palo, S. E. and Avery, S. K.: Observations of the quasi-two-day wave in the middle and lower atmosphere over Christmas Island, J. Geophys. Res.-Atmos., 101, 12833-12846, 1996.

Palo, S. E., Roble, R. G., and Hagan, M. E.: Middle atmosphere effects of the quasi-two-day wave determined from a General Circulation Model, Earth Planets Space, 51, 629-647, 1999.

Palo, S. E., Forbes, J. M., Zhang, X., Russell, J. M., and Mlynczak, M. G.: An eastward propagating two-day wave: Evidence for nonlinear planetary wave and tidal coupling in the mesosphere and lower thermosphere, Geophys. Res. Lett., 34, L07807, doi:10.1029/2006g1027728, 2007.

Pancheva, D., Mitchell, N. J., Manson, A. H., Meek, C. E., Jacobi, C., Portnyagin, Y., Merzlyakov, E., Hocking, W. K., MacDougall, J., Singer, W., Igarashi, K., Clark, R. R., Riggin, D. M., Franke, S. J., Kurschner, D., Fahrutdinova, A. N., Stepanov, A. M., Kashcheyev, B. L., Oleynikov, A. N., and Muller, H. G.: Variability of the quasi-2-day wave observed in the MLT region during the PSMOS campaign of June-August 1999, J. Atmos. Sol.-Terr. Phy., 66, 539-565, doi:10.1016/j.jastp.2004.01.008, 2004.

Pfister, L.: Baroclinic Instability of Easterly Jets with Applications to the Summer Mesosphere, J. Atmos. Sci., 42, 313-330, 1985.

Phillips, A.: Simultaneous Observations of the Quasi 2-Day Wave at Mawson, Antarctica, and Adelaide, South-Australia, J. Atmos. Terr. Phys., 51, 119-124, 1989.

Plumb, R. A.: Baroclinic Instability of the Summer Mesosphere - a Mechanism for the Quasi-2-Day Wave, J. Atmos. Sci., 40, 262270, 1983.

Plumb, R. A., Vincent, R. A., and Craig, R. L.: The Quasi-2-Day Wave Event of January 1984 and Its Impact on the Mean Mesospheric Circulation, J. Atmos. Sci., 44, 3030-3036, 1987.

Prata, A. J.: The 4-Day Wave, J. Atmos. Sci., 41, 150-155, 1984.

Riggin, D. M., Lieberman, R. S., Vincent, R. A., Manson, A. H., Meek, C. E., Nakamura, T., Tsuda, T., and Portnyagin, Y. I.: The 2-day wave during the boreal summer of 1994, J. Geophys. Res.Atmos., 109, D08110, doi:10.1029/2003jd004493, 2004.
Rodgers, C. D. and Prata, A. J.: Evidence for a Traveling 2-Day Wave in the Middle Atmosphere, J. Geophys. Res.-Oc. Atm., 86, 9661-9664, 1981.

Rojas, M. and Norton, W.: Amplification of the 2-day wave from mutual interaction of global Rossby-gravity and local modes in the summer mesosphere, J. Geophys. Res.-Atmos., 112, D12114, doi:10.1029/2006jd008084, 2007.

Salby, M. L. and Roper, R. G.: Long-Period Oscillations in the Meteor Region, J. Atmos. Sci., 37, 237-244, 1980.

Salby, M. L.: The 2-Day Wave in the Middle Atmosphere - Observations and Theory, J. Geophys. Res.-Oc. Atm., 86, 9654-9660, 1981.

Salby, M. L. and Callaghan, P. F.: Seasonal amplification of the 2day wave: Relationship between normal mode and instability, J. Atmos. Sci., 58, 1858-1869, 2001.

Salby, M. L. and Callaghan, P. F.: Interaction of the 2-day wave with solar tides, J. Geophys. Res.-Atmos., 113, D14121, doi:10.1029/2006jd007892, 2008.

Sandford, D. J., Schwartz, M. J., and Mitchell, N. J.: The wintertime two-day wave in the polar stratosphere, mesosphere and lower thermosphere, Atmos. Chem. Phys., 8, 749-755, 2008, http://www.atmos-chem-phys.net/8/749/2008/.

Smith, A. K.: The origin of stationary planetary waves in the upper mesosphere, J. Atmos. Sci., 60, 3033-3041, 2003.

Thayaparan, T., Hocking, W. K., MacDougall, J., Manson, A. H., and Meek, C. E.: Simultaneous observations of the 2-day wave at London (43 degrees N, 81 degrees W) and Saskatoon (52 degrees $\mathrm{N}, 107$ degrees $\mathrm{W}$ ) near $91 \mathrm{~km}$ altitude during the two years of 1993 and 1994, Ann. Geophys., 15, 1324-1339, 1997, http://www.ann-geophys.net/15/1324/1997/.

Tsuda, T., Kato, S., and Vincent, R. A.: Long Period Wind Oscillations Observed by the Kyoto Meteor Radar and Comparison of the Quasi-2-Day Wave with Adelaide Hf Radar Observations, J. Atmos. Terr. Phys., 50, 225-230, 1988.

Ward, W. E., Wang, D. Y., Solheim, B. H., and Shepherd, G. G.: Observations of the two-day wave in WINDII data during January, 1993, Geophys. Res. Lett., 23, 2923-2926, 1996.

Wu, D. L., Hays, P. B., Skinner, W. R., Marshall, A. R., Burrage, M. D., Lieberman, R. S., and Ortland, D. A.: Observations of the Quasi 2-Day Wave from the High-Resolution Doppler Imager on Uars, Geophys. Res. Lett., 20, 2853-2856, 1993.

Wu, D. L., Fishbein, E. F., Read, W. G., and Waters, J. W. Excitation and evolution of the quasi-2-day wave observed in UARS/MLS temperature measurements, J. Atmos. Sci., 53, 728 $738,1996$. 